\title{
Association of Parental Overweight and Cardiometabolic Diseases and Pediatric Adiposity and Lifestyle Factors with Cardiovascular Risk Factor Clustering in Adolescents
}

\author{
Chun-Ying Lee ${ }^{1,2}$, Wei-Ting Lin ${ }^{3}$, Sharon Tsai ${ }^{4}$, Yu-Chan Hung ${ }^{1}$, Pei-Wen Wu ${ }^{1}$, \\ Yu-Cheng Yang ${ }^{1}$, Te-Fu Chan ${ }^{5,6}$, Hsiao-Ling Huang ${ }^{7}$, Yao-Lin Weng ${ }^{8}$, Yu-Wen Chiu ${ }^{9}$, \\ Chia-Tsuan Huang ${ }^{2}$ and Chien-Hung Lee ${ }^{1,10, *}$ \\ 1 Department of Public Health, College of Health Sciences, Kaohsiung Medical University, \\ Kaohsiung 807, Taiwan; cying@ms19.hinet.net (C.-Y.L.); ych0610@gmail.com (Y.-C.H.); \\ catstar1211@gmail.com (P.-W.W.); 119920929@gmail.com (Y.-C.Y.) \\ 2 Department of Family Medicine, Kaohsiung Medical University Hospital, Kaohsiung 807, Taiwan; \\ chtshu@cc.kmu.edu.tw \\ 3 Institute of Environmental and Occupational Health Sciences, National Yang Ming University, \\ Taipei 112, Taiwan; wtlin0123@gmail.com \\ 4 Department of Laboratory Medicine, Kaohsiung Municipal Hsiao-Kang Hospital, \\ Kaohsiung 807, Taiwan; 0870718@kmhk.org.tw \\ 5 Department of Obstetrics and Gynecology, Graduate Institute of Medicine, College of Medicine, \\ Kaohsiung Medical University, Kaohsiung 807, Taiwan; tefu.chan@msa.hinet.net \\ 6 Department of Obstetrics and Gynecology, Kaohsiung Medical University Hospital, \\ Kaohsiung Medical University, Kaohsiung 807, Taiwan \\ 7 Department of Oral Hygiene, College of Dental Medicine, Kaohsiung Medical University, \\ Kaohsiung 807, Taiwan; hhuang@kmu.edu.tw \\ 8 Department of Food and Nutrition, Providence University, Taichung 433, Taiwan; ylweng@pu.edu.tw \\ 9 Health Policy and Systems Management Program, Health Sciences Center, School of Public Health, \\ Louisiana State University, New Orleans, LA 70803, USA; ychiu@lsuhsc.edu \\ 10 Research Center for Environmental Medicine, Kaohsiung Medical University, No. 100 Shih-Chuan 1st Road, \\ Kaohsiung 807, Taiwan \\ * Correspondence: cnhung@kmu.edu.tw; Tel.: +886-7-312-1101 (ext. 2141); Fax: +886-7-311-0811
}

Received: 21 May 2016; Accepted: 5 September 2016; Published: 13 September 2016

\begin{abstract}
Cardiometabolic risk factors or their precursors are observed in childhood and may continue into adulthood. We investigated the effects of parental overweight and cardiometabolic diseases and pediatric lifestyle factors on the clustering of cardiovascular risk factors among adolescents, and examined the mediating and modifying effects of pediatric adiposity on these associations. Representative adolescents ( $n=2727$; age, $12-16$ years) were randomly recruited through multistage stratified sampling from 36 schools in Southern Taiwan. Adolescent and parent surveys were conducted in schools and participant homes, respectively. Their demographic factors, diet patterns, and physical, anthropometric, and clinical parameters were collected and analyzed. Adolescents with 1-2 and $\geq 3$ risk components for pediatric metabolic syndrome (MetS) were defined as potential MetS (pot-MetS) and MetS, respectively. Adolescents whose parents were overweight/obese, or with diabetes and hypertension had a higher prevalence ratio of pot-MetS and MetS (1.5-1.6 and 1.9-4.2-fold, respectively). Low physical activity (<952.4 MET.min/week), long screen time $(\geq 3 \mathrm{~h} /$ day) and high sugar-sweetened beverage intake $(>500 \mathrm{~mL} /$ day) were associated with a 3.3- $(95 \%$ confidence intervals $(C I)=1.5-7.3), 2.2-(95 \% \mathrm{CI}=1.1-4.4)$, and 26.9 -fold $(95 \% \mathrm{CI}=3.2-229.0)$ odds ratio (OR) of MetS, respectively. Pediatric body mass index (BMI) accounted for $18.8 \%-95.6 \%$ and $16.9 \%-60.3 \%$ increased prevalence ratios of these parental and pediatric risk factors for MetS. The OR of pot-MetS + MetS for sugar-sweetened beverage consumption was multiplicatively enhanced among adolescents with overweight/obesity (combined OR, 8.6-fold (95\% CI $=4.3-17.3$ ); $p$ for
\end{abstract}


multiplicative interaction, 0.009). The results suggest that parental overweight and cardiometabolic diseases and pediatric sedentary and high sugar-intake lifestyles correlate with the development of adolescent MetS, and an elevated child BMI explains a part of these associations. Pediatric adiposity might be multiplicatively associated with sugar-sweetened beverage consumption for enhancing the MetS prevalence ratio among adolescents.

Keywords: adolescent; adiposity; cardiometabolic risk factors; metabolic syndrome; parental disease; screen time; sugar-sweetened beverages

\section{Introduction}

Type 2 diabetes mellitus (T2DM) and its long-term complications, including cardiovascular diseases, stroke, and chronic kidney failure, are global health concerns that substantially affect life expectancy and mortality [1]. In adults, principal determinants, such as abdominal obesity, dyslipidemia, hypertension, and dysglycemia, and the clustering of these disorders have been reported [2]. Nevertheless, some of these risk factors or their precursors are observed in childhood [3-5], and may persist into adulthood [6]. Metabolic syndrome (MetS) is a cluster of cardiometabolic risk factors. A longitudinal study revealed that pediatric MetS predisposes adults to a high risk of high carotid intima-media thickness and T2DM [7]; however, the risk can be reduced to normal by resolving MetS before adulthood [8]. These findings emphasize that preventing and resolving pediatric MetS is crucial for preventing the development of these cardiometabolic disorders in adulthood.

Parent-child dyad studies have suggested that obesity and certain cardiometabolic risk factors are shared across generations [9-11]. A study investigating longitudinal cardiovascular risk found that obese children with an obese parent were $21.2 \%$ likely to be eligible for bariatric surgery in adulthood [12]. However, whether children with parental MetS-related diseases are at a high risk of MetS is uncertain. If such a risk exists, whether the generational effect is associated with pediatric adiposity remains to be investigated. Lifestyle risk factors, such as unhealthy diets, physical inactivity, and excessive screen time (ST), have been associated with increased cardiometabolic risk among children and adolescents [13-17]. MetS is common in obese youths [18], and numerous unhealthy behaviors have been identified as obesogenic risk factors [19-21]. Therefore, the mediating and/or modifying effects of obesity on the association between lifestyle risk factors and pediatric MetS warrant further investigation.

In Taiwan, childhood overweight and obesity have received extensive attention as major health concerns. According to a series of national surveys conducted by Taiwan's Ministry of Education between 1991 and 2003, the prevalence of overweight/obesity among adolescents aged 13-18 years increased by $53.7 \%$ (from $16.4 \%$ to $25.2 \%$ ) in boys and $70.8 \%$ in girls (from $8.9 \%$ to $15.2 \%$ ) [22]. With the markedly high increase in childhood overweight and obesity, the clustering of cardiometabolic risk factors among adolescents has become a critical concern in pediatric health care. The present study had two aims: first, to evaluate the effects of parental overweight and MetS-related diseases in addition to pediatric lifestyle risk factors on different degrees of clustering of cardiovascular risk factors, and second, to investigate the mediating and modifying effects of pediatric adiposity on the association between these factors and cardiometabolic disorders among Taiwanese adolescents.

\section{Materials and Methods}

\subsection{Participants}

In this cross-sectional study, we used data from the Multilevel Risk Profiles for Adolescent Metabolic Syndrome study, a large-scale survey designed to obtain estimates on diet, physical activity (PA), and cardiometabolic disease-related risk markers from a representative adolescent population in 
Southern Taiwan $[4,5,23,24]$. The target population comprised adolescents who were included in the entry lists of 112 junior high schools' grades 7-9 (age, 12-16 years) from 2007 to 2009 in Kaohsiung City, Pingtung County, and Taitung County of Southern Taiwan; these three areas have diverse economic levels. The complex sampling approach and research procedures have been detailed previously [4]. In brief, a multistage, geographically-stratified cluster sampling technique was used to enroll study participants from the defined population. Overall, 3881 students were randomly enrolled from 36 randomly selected schools. Among them, 3784 (97.5\%) agreed to participate in the questionnaire survey and anthropometric measurements; 2727 (72.1\%) of these students underwent biochemical blood examinations. The study was commenced after the Institutional Review Board of Kaohsiung Medical University approved the research protocol, and written informed assent and consent were respectively obtained from the adolescents and their parents or guardians.

\subsection{Data Collection}

Two structured questionnaires developed for adolescents and their parents were used to collect the research information. The adolescent survey was conducted in schools, where adolescent questionnaires were completed with the assistance of trained research staff and school teachers. We collected data on demographic characteristics, individual disease history, PA, sedentary lifestyle factors, dietary consumption, and the status of alcohol intake and cigarette smoking. The parent survey was conducted in participant homes, where a self-administered questionnaire with a clear fill description was completed. The data obtained comprised socioeconomic factors, body weight, height, disease history, dietary intake, PA, alcohol drinking and cigarette smoking. Body mass index (BMI) was determined by dividing the weight $(\mathrm{kg})$ by the square of the height $\left(\mathrm{m}^{2}\right)$. Normal weight was defined as a BMI of $\leq 23.9$, overweight as $24 \leq \mathrm{BMI}<26.9$, and obesity as BMI $\geq 27$ according to the adult criteria determined by Taiwan's Department of Health [25]. Disease data included hypertension, T2DM, cardiovascular diseases, and other chronic diseases. A positive disease history was defined as either the father or mother having a clinically-diagnosed disease.

A scale containing nine questions was used to measure the PA of adolescents on both weekdays and weekends. The activity data were converted to metabolic equivalent task (MET) measurements, and the overall MET-min per week was calculated as the product of the MET level of activity, time (minutes) spent in each activity per day, and the number of days per week [26]. Information on sedentary lifestyle factors included time spent on watching television, playing video games, working on a computer at home or in an internet cafe, reading books, and after-school tutoring. ST was defined as the time spent on activities performed in front of a screen; it was measured as the average time spent on watching television, playing video games, and using the computer per day in a typical week (including weekdays and weekends). Reading time was defined as the time spent on reading-related sedentary activities; it was measured as the average time spent on reading books and after-school tutoring per day in a typical week.

The daily dietary intake over the preceding one month was analyzed by using a semi-quantitative food-frequency questionnaire comprising 23 food groups. The Taiwan Food and Drug Administration established a Food and Nutrients Databank for foods often consumed by Taiwanese people [27]. We used this databank and individual dietary data to estimate the daily total calorie intake. Data on the consumption of soft drinks, sweetened teas, and fruit drinks were derived from the responses to the food-frequency questionnaire. Sugar-sweetened beverage (SSB) drinkers were defined as participants who had ingested at least one serving of these drinks per week in the previous month; the daily amount of SSB intake was calculated for each participant. A positive status for drinking or smoking was defined as participants who reported drinking $\geq 1$ drinks of any types of alcoholic beverages or smoking $\geq 1$ cigarettes in the preceding month.

\subsection{Anthropometric and Clinical Measurements}

Certified examiners performed anthropometric assessments in the adolescents to obtain data on height, weight, waist circumference, body fat, and blood pressure (BP). Because the adolescent 
BMI varies according to age and sex, we converted the BMI to age- and sex-standardized Z-scores on the basis of Taiwanese adolescent growth charts and presented the value as zBMI for data analysis. Bodyweight was classified according to adolescent BMI and the age- and sex-specific BMI cutoff points for adolescent overweight and obesity determined by Taiwan's Ministry of Health and Welfare [28]. A mercury sphygmomanometer was used to measure blood pressure according to the American Heart Association guidelines [29]. Two blood pressure measurements were performed at five-minute intervals, and the average systolic and diastolic blood pressure readings were calculated for analysis. After collecting the questionnaire data, the researchers required three weeks to obtain informed consent from the parents of all participating students, following which the blood examinations were conducted. Clinical samples were obtained from the adolescents whose parents or guardians offered informed consent. Moreover, blood samples after a 10-h overnight fast were collected in the morning through venipuncture at the health center of each school. Overnight fasting was confirmed through face-to-face inquiries regarding the food ingested between the preceding night and the examination morning. Using commercially available reagents, we measured the circulating levels of high-density lipoprotein cholesterol (HDL-C), triglycerides, and fasting plasma glucose by using a chemistry autoanalyzer (TBA-c16000 automatic analyzer, Toshiba, Tokyo, Japan) [30].

\subsection{Definition of Metabolic Syndrome}

No universal diagnostic criteria exists for pediatric MetS. Therefore, to investigate its associated risk factors among adolescents, the harmonized criteria proposed by a joint statement from six obesity-, diabetes-, and heart-related major societies were used to define MetS [31]. The definition of MetS includes five risk components: (1) elevated fasting plasma glucose ( $\geq 100 \mathrm{mg} / \mathrm{dL})$; (2) decreased HDL-C males, $<40 \mathrm{mg} / \mathrm{dL}(1.0 \mathrm{mmol} / \mathrm{L})$ and females, $<50 \mathrm{mg} / \mathrm{dL}(1.3 \mathrm{mmol} / \mathrm{L}))$; (3) elevated triglycerides $\geq 150 \mathrm{mg} / \mathrm{dL}(1.7 \mathrm{mmol} / \mathrm{L}$ )); (4) central obesity (waist circumference: $\geq 90 \mathrm{~cm}$ and $\geq 80 \mathrm{~cm}$ for Asian males and females, respectively); and (5) elevated BP (systolic BP, $\geq 130 \mathrm{mmHg}$ and diastolic BP, $\geq 85 \mathrm{mmHg}$ ). Participants with $\geq 3$ risk components were defined as having MetS. To investigate the effects of risk factors on the potential status of MetS (pot-MetS) in adolescents, we defined participants who have one or two risk components as pot-MetS. Participants without any risk components were defined as non-MetS risk factor (non-MetS) and were considered the control group.

\subsection{Statistical Analysis}

In the study areas, a high proportion of aboriginal people live in Taitung County (approximately $30 \%$ of the inhabitants). To investigate possible between-race differences in effects, Taitung's respondents were oversampled to ensure sufficient adolescents in the diverse ethnicity groups. Survey-data modules were used to adjust for the multistage sampling design and unequal sampling probabilities (Stata v13, StataCorp., College Station, TX, USA), so as to final results can be representative of the student population of Southern Taiwan. The weighted results were expressed as means, standard errors, or percentages of variables. For data interpretation, certain continuous factors were analyzed at a categorical scale as follows: PA, <952.4, 952.4-2140.4, and $\geq 2140.5 \mathrm{MET} \cdot \mathrm{min} /$ week (tertile); ST, $<1.5,1.5-2.9$, and $\geq 3 \mathrm{~h} /$ day; reading time, $<1.5,1.5-2.9$, and $\geq 3 \mathrm{~h} /$ day; SSB intake, non-intake, 1-500 and $>500 \mathrm{~mL} /$ day. Because three MetS-associated outcomes (non-MetS, pot-MetS, and MetS) were defined, we used multinomial logistic regression models to determine the prevalence ratio of pot-MetS or MetS relative to the non-MetS [32]. The adjusted odds ratio (aOR) with its $95 \%$ confidence intervals (CIs), obtained by exponentiating the corresponding regression coefficient, was used to evaluate the association between the study variables and the specific MetS status after adjustment for the effects of potential confounding factors. Parameters that changed the effect of interest by $>10 \%$ or had been previously established as confounders were considered the potential confounding variables [33]. These confounding factors were age, gender, ethnicity, residential area, total calorie intake, alcohol-drinking status, and cigarette-smoking status. The adjusted mean is a statistic calculated from the prediction of a fitted model at a fixed value of the investigated variable 
and the average values of the remaining covariates. This statistic was used to compare the mean difference in adolescent risk factors across MetS-associated conditions. Because child BMI substantially affects MetS, we evaluated the excess prevalence ratio of pot-MetS and MetS that is explained by child BMI for each risk factor by using the formula $\left(\mathrm{aOR}_{1}-\mathrm{aOR}_{2}\right) /\left(\mathrm{aOR}_{1}-1\right)$-where $a \mathrm{aR}_{1}$ is the prevalence ratio obtained from the covariate-adjusted base model, $\mathrm{aOR}_{2}$ is the prevalence ratio after additionally adjusting for the child $\mathrm{BMI}$, and $\mathrm{aOR}_{1}-1$ is the excess prevalence ratio of a risk factor [34]. Multivariable logistic regression models with two parameters and their cross-product terms were used to analyze the potential synergistic effect by using a multiplicative model. The synergism index (SI), recommended by Rothman, was calculated to assess the empirical deviation from the additive interaction relationship [35,36]. An SI value that significantly differed from the null suggests an additive interaction effect.

\section{Results}

After adjusting the complex sampling design, the prevalence of pot-MetS and MetS among adolescents in Southern Taiwan was 39.3\% and 3.3\%, respectively (Table 1). The MetS group had a higher percentage of males than did the non-MetS group (63.4\% vs. $48.0 \%)$. No notable discrepancy was observed in the distribution of age, ethnicity, residential area, total calorie intake, alcohol drinking, and cigarette smoking across adolescents in the non-MetS, pot-MetS and MetS groups. Adolescents with a poor MetS condition tended to have decreased physical activity and an increased SSB intake, central obesity, zBMI value, waist circumference, BP, serum triglyceride, and plasma glucose and were likely to have a low HDL-C level.

Table 1. Demographic backgrounds and risk factors of adolescents in relation to metabolic syndrome status.

\begin{tabular}{|c|c|c|c|c|c|c|}
\hline Factors & Non-MetS & Pot-MetS & Diff. $^{1}$ & MetS & Diff. $2^{1}$ & $p$ Value $^{2}$ \\
\hline Study number & 1565 & 1077 & & 85 & & \\
\hline \multicolumn{7}{|l|}{ Design-adjusted distribution ${ }^{3}$} \\
\hline Prevalence pattern, $\%$ & 57.4 & 39.3 & & 3.3 & & $<0.001$ \\
\hline \multicolumn{7}{|l|}{ Demographic and risk factor } \\
\hline Age (year), mean $\pm \mathrm{SE}$ & $13.6 \pm 0.1$ & $13.5 \pm 0.1$ & -0.1 & $13.6 \pm 0.1$ & -0.1 & 0.454 \\
\hline Male, \% & 49.7 & 46.1 & -3.6 & 64.1 & 14.4 * & 0.027 \\
\hline \multicolumn{7}{|l|}{ Ethnicity, \% } \\
\hline Fukienese & 67.3 & 70.6 & & 67.2 & & 0.214 \\
\hline Hakka & 10.6 & 7.3 & & 11.9 & & \\
\hline Aboriginal & 3.1 & 4.6 & & 3.5 & & \\
\hline Others & 19.0 & 17.5 & & 17.3 & & \\
\hline \multicolumn{7}{|l|}{ Residential area, \% } \\
\hline Kaohsiung & 61.4 & 52.6 & & 51.3 & & 0.300 \\
\hline Pingtung & 31.3 & 37.7 & & 39.7 & & \\
\hline Taitung & 7.3 & 9.8 & & 9.0 & & \\
\hline Total calorie intake $(\mathrm{kcal} / \mathrm{d})$, mean $\pm \mathrm{SE}$ & $2092.9 \pm 27.6$ & $2050.5 \pm 49.8$ & -42.4 & $2127.3 \pm 53.0$ & 34.4 & 0.449 \\
\hline Physical activity (MET $\cdot$ min/week), mean $\pm \mathrm{SE}$ & $2474.6 \pm 99.3$ & $2409.4 \pm 125.1$ & -65.2 & $1693.1 \pm 179.8$ & $-781.5 *$ & 0.001 \\
\hline SSB intake (mL/day), mean \pm SE & $446.3 \pm 10.7$ & $478.3 \pm 12.9$ & $32.0 *$ & $562.2 \pm 22.2$ & $115.9^{*}$ & $<0.001$ \\
\hline Alcohol drinking, \% & 13.0 & 9.3 & -3.7 & 10.5 & -2.5 & 0.108 \\
\hline Cigarette smoking, \% & 2.2 & 2.7 & 0.5 & 1.2 & -1.0 & 0.638 \\
\hline Central obesity, \% & 0.0 & 28.3 & $28.3 *$ & 89.9 & $89.9^{*}$ & $<0.001$ \\
\hline $\mathrm{zBMI}$, mean $\pm \mathrm{SE}^{4}$ & $-0.3 \pm 0.03$ & $0.3 \pm 0.07$ & $0.6^{*}$ & $1.9 \pm 0.13$ & $2.2 *$ & $<0.001$ \\
\hline \multicolumn{7}{|l|}{ MetS component, mean $\pm \mathrm{SE}$} \\
\hline Waist circumference $(\mathrm{cm})$ & $68.8 \pm 0.4$ & $75.5 \pm 1.2$ & $6.7^{*}$ & $94.7 \pm 1.6$ & $25.9 *$ & $<0.001$ \\
\hline Systolic blood pressure (mmHg) & $106.4 \pm 0.5$ & $112.7 \pm 0.7$ & $6.3^{*}$ & $130.6 \pm 2.1$ & $24.1 *$ & $<0.001$ \\
\hline Diastolic blood pressure (mmHg) & $63.4 \pm 0.3$ & $66.5 \pm 0.5$ & $3.1 *$ & $74.0 \pm 1.7$ & $10.5^{*}$ & $<0.001$ \\
\hline Serum triglyceride (mg/dL) & $68.5 \pm 0.8$ & $86.9 \pm 3.2$ & $18.4^{*}$ & $138.3 \pm 9.0$ & $69.8 *$ & $<0.001$ \\
\hline Serum high-density lipoprotein cholesterol (mg/dL) & $61.7 \pm 0.6$ & $51.8 \pm 2.2$ & $-10.0 *$ & $45.6 \pm 1.9$ & $-16.1^{*}$ & $<0.001$ \\
\hline Fasting plasma glucose $(\mathrm{mg} / \mathrm{dL})$ & $89.5 \pm 0.4$ & $92.8 \pm 1.5$ & $3.2^{*}$ & $97.9 \pm 1.7$ & $8.4^{*}$ & $<0.001$ \\
\hline
\end{tabular}

Abbreviations: non-MetS, non-metabolic syndrome; pot-MetS, potential metabolic syndrome; MetS, metabolic syndrome. Adolescents with 0,1-2 and $\geq 3$ risk components for MetS were defined as non-MetS, pot-MetS and MetS, respectively; ${ }^{*} p<0.05 .{ }^{1}$ Diff. 1 and Diff.2 denote the difference in mean or proportion for pot-MetS vs. non-MetS and MetS vs. non-MetS, respectively; ${ }^{2} p$ values for mean or percentage differences across MetS groups; ${ }^{3}$ Data was adjusted for sample weight and the complex study design; ${ }^{4}$ zBMI denotes an age-sex-standardized $z$-score for BMI value.

The association between parental risk factors and adolescent MetS status is shown in Table 2. Parental overweight/obesity was observed to be associated with a higher cardiometabolic prevalence 
ratio in adolescents ( $\mathrm{aOR}=1.5$ for pot-MetS in both father and mother and 2.2 for MetS in the mother). In addition, both parents being overweight/obese predisposed adolescents to a 2.3- and 3.2-fold higher prevalence ratio of pot-MetS and MetS, respectively. Adolescents with parental diabetes and hypertension had a 1.7- and 1.5-fold aOR of pot-MetS and 5.1- and 2.7-fold aOR of MetS, respectively, compared with those whose parents had no disease history. The prevalence ratio of MetS was also higher than that of pot-MetS among adolescents with parental diabetes and hypertension $(\mathrm{aOR}$ ratio $=3.0$ and 1.8 , respectively; $p<0.03$ ).

Table 2. Adjusted odds ratios of adolescent potential metabolic syndrome and metabolic syndrome associated with parental risk factors.

\begin{tabular}{|c|c|c|c|c|c|c|c|c|c|}
\hline \multirow{2}{*}{ Factors } & \multicolumn{2}{|c|}{ Non-MetS } & \multicolumn{2}{|c|}{ Pot-MetS } & \multicolumn{3}{|c|}{ MetS } & \multicolumn{2}{|c|}{ MetS vs. Pot-MetS } \\
\hline & $\%$ & $\%$ & $\mathrm{aOR}^{1}$ & $(95 \% \mathrm{CI})$ & $\%$ & $\mathrm{aOR}^{1}$ & $(95 \% \mathrm{CI})$ & aOR Ratio ${ }^{1}$ & $(95 \% \mathrm{CI})$ \\
\hline \multicolumn{10}{|l|}{ Parental bodyweight } \\
\hline \multicolumn{10}{|l|}{ Father } \\
\hline NW & 45.9 & 35.6 & 1.0 & & 28.5 & 1.0 & & 1.0 & \\
\hline $\mathrm{OW}+\mathrm{OB}$ & 54.1 & 64.4 & 1.5 & $(1.3-1.8)$ & 71.5 & 2.0 & $(0.9-4.4)$ & 1.3 & $(0.6-3.0)$ \\
\hline \multicolumn{10}{|l|}{ Mother } \\
\hline NW & 73.1 & 63.1 & 1.0 & & 54.3 & 1.0 & & 1.0 & \\
\hline $\mathrm{OW}+\mathrm{OB}$ & 26.9 & 36.9 & 1.5 & $(1.2-1.9)$ & 45.7 & 2.2 & $(1.2-4.1)$ & 1.4 & $(0.8-2.5)$ \\
\hline \multicolumn{10}{|l|}{ Father and mother } \\
\hline Both NW & 35.2 & 25.3 & 1.0 & & 20.9 & & & & \\
\hline One OW + OB & 49.2 & 48.0 & 1.4 & $(1.0-1.9)$ & 46.2 & 1.5 & $(0.5-4.6)$ & 1.1 & $(0.4-3.2)$ \\
\hline Both OW + OB & 15.7 & 26.6 & 2.3 & $(1.6-3.3)$ & 32.9 & 3.2 & $(1.3-8.1)$ & 1.4 & $(0.6-3.4)$ \\
\hline \multicolumn{10}{|l|}{ Parental disease } \\
\hline \multicolumn{10}{|l|}{ Diabetes mellitus } \\
\hline No & 95.7 & 93.2 & 1.0 & & 81.0 & 1.0 & & 1.0 & \\
\hline Yes & 4.3 & 6.8 & 1.7 & $(1.1-2.7)$ & 19.0 & 5.1 & $(2.7-9.7)$ & 3.0 & $(1.3-6.8)$ \\
\hline \multicolumn{10}{|l|}{ Hypertension } \\
\hline No & 87.4 & 82.3 & 1.0 & & 72.0 & 1.0 & & 1.0 & \\
\hline Yes & 12.6 & 17.7 & 1.5 & $(1.1-2.0)$ & 28.0 & 2.7 & $(1.4-5.3)$ & 1.8 & $(1.1-3.1)$ \\
\hline \multicolumn{10}{|l|}{ Dyslipidemia } \\
\hline No & 86.9 & 87.6 & 1.0 & & 81.1 & 1.0 & & 1.0 & \\
\hline Yes & 13.1 & 12.4 & 1.0 & $(0.7-1.3)$ & 18.9 & 1.5 & $(0.7-3.3)$ & 1.6 & $(0.7-3.3)$ \\
\hline
\end{tabular}

Figure S1 illustrates the distribution of overweight and obesity among adolescents with different MetS status. A considerable decrease in the proportions of normal weight, overweight and obesity was observed in adolescents without any metabolic abnormality, whereas the corresponding body weight proportions notably increased in adolescents with MetS. Adolescent overweight/obesity was associated with a 3.9- and 1461.2-fold elevated prevalence ratio of pot-MetS and MetS, respectively (Table 3). The adjusted mean of the BMI for adolescents with MetS was $7.4 \mathrm{~kg} / \mathrm{m}^{2}$ higher than that for adolescents with pot-MetS.

Table 3 presents the association between adolescent lifestyle factors and their MetS conditions. Compared with adolescents with a high level of PA ( $\geq 2140.5$ MET $\cdot$ min/week), those with moderate (952.4-2140.4 MET·min/week) and low (<952.4 MET·min/week) levels of PA had a 2.5- and 4.4-fold higher aOR of MetS, respectively. Long ST ( $\geq 3 \mathrm{~h} /$ day) was associated with a higher MetS prevalence ratio, with adolescents with MetS having a $0.30 \mathrm{~h} /$ day longer ST than did non-MetS adolescents. Adolescents who consumed heavy amounts of SSB ( $>500 \mathrm{~mL} /$ day) had a 1.7- and 30.2-fold higher aOR of pot-MetS and MetS, respectively. For moderate and low levels of PA, a heterogeneous prevalence ratio was identified between pot-MetS and MetS (aOR ratio, 2.5 and 3.8, respectively). Considering SSB intake, the prevalence ratio of MetS was higher than that of pot-MetS (aOR ratio, 13.0 and 17.7 for 
1-500 and $>500 \mathrm{~mL} /$ day of SSB intake, respectively), and adolescents with MetS had a $68.1 \mathrm{~mL} /$ day higher SSB intake than did those with pot-MetS.

Table 3. Adjusted odds ratios and means of adolescent potential metabolic syndrome and metabolic syndrome associated with adolescent bodyweight and lifestyle factors.

\begin{tabular}{|c|c|c|c|c|c|c|c|c|c|}
\hline \multirow{2}{*}{ Factors } & \multicolumn{2}{|c|}{ Non-MetS } & \multicolumn{2}{|c|}{ Pot-MetS } & \multicolumn{3}{|c|}{ MetS } & \multicolumn{2}{|c|}{ MetS vs. Pot-MetS } \\
\hline & $\%$ & $\%$ & $\mathrm{aOR}^{1}$ & $(95 \% \mathrm{CI})$ & $\%$ & $\mathrm{aOR}^{1}$ & $(95 \% \mathrm{CI})$ & aOR Ratio $^{1}$ & $(95 \% \mathrm{CI})$ \\
\hline \multicolumn{10}{|l|}{ Bodyweight $^{3}$} \\
\hline Normal & 78.2 & 50.0 & 1.0 & & 0.3 & 1.0 & & 1.0 & \\
\hline Overweight + Obesity & 21.9 & 50.0 & 3.9 & $(2.6-5.9)$ & 99.7 & 1461.2 & (198.8-10741.8) & 373.9 & $(50.7-2759.0)$ \\
\hline Adjusted BMI mean ${ }^{1}$ & 19.9 & 22.9 & $3.0^{2, *}$ & & 30.3 & $10.4^{2, *}$ & & $7.4^{2, *}$ & \\
\hline \multicolumn{10}{|l|}{$\begin{array}{l}\text { Physical activity } \\
\text { (MET·min/week) }\end{array}$} \\
\hline$\geq 2140.5$ & 32.5 & 30.7 & 1.0 & & 16.4 & 1.0 & & 1.0 & \\
\hline$\overline{952.4-2140.4}$ & 43.4 & 41.8 & 1.0 & $(0.7-1.3)$ & 45.2 & 2.5 & $(1.2-5.0)$ & 2.5 & $(1.3-5.1)$ \\
\hline$<952.4$ & 24.1 & 27.5 & 1.1 & $(0.8-1.5)$ & 38.4 & 4.4 & $(2.2-8.6)$ & 3.8 & $(1.9-7.8)$ \\
\hline Adjusted mean ${ }^{1}$ & 2454.1 & 2454.2 & $0.2^{2}$ & & 1514.1 & $-940.0^{2, *}$ & & $-940.1^{2, *}$ & \\
\hline \multicolumn{10}{|l|}{ Screen time (h/day) } \\
\hline$<1.5$ & 49.4 & 45.9 & 1.0 & & 36.8 & 1.0 & & 1.0 & \\
\hline $1.5-2.9$ & 34.7 & 37.2 & 1.2 & $(0.9-1.6)$ & 38.9 & 1.5 & $(0.8-2.8)$ & 1.3 & $(0.7-2.3)$ \\
\hline$\geq 3$ & 15.9 & 16.9 & 1.2 & $(0.9-1.6)$ & 24.3 & 2.1 & $(1.1-3.9)$ & 1.8 & $(0.9-3.5)$ \\
\hline$\overline{\text { Adjusted mean }}{ }^{1}$ & 1.63 & 1.70 & $0.07^{2}$ & & 1.93 & $0.30^{2, *}$ & & $0.22^{2}$ & \\
\hline \multicolumn{10}{|l|}{ Reading time (h/day) } \\
\hline$<1.5$ & 47.1 & 52.3 & 1.0 & & 56.2 & 1.0 & & 1.0 & \\
\hline $1.5-2.9$ & 43.5 & 38.5 & 0.8 & $(0.7-1.0)$ & 31.3 & 0.6 & $(0.4-1.0)$ & 0.8 & $(0.4-1.3)$ \\
\hline$\geq 3$ & 9.4 & 9.2 & 1.0 & $(0.7-1.5)$ & 12.5 & 1.2 & $(0.3-4.2)$ & 1.2 & $(0.3-4.6)$ \\
\hline $\bar{A}$ djusted mean ${ }^{1}$ & 1.51 & 1.45 & $-0.06^{2}$ & & 1.36 & $-0.16^{2}$ & & $-0.10^{2}$ & \\
\hline \multicolumn{10}{|l|}{$\begin{array}{l}\text { Sugar-sweetened } \\
\text { beverage intake (mL/day) }\end{array}$} \\
\hline Non-intake & 14.0 & 10.7 & 1.0 & & 0.8 & 1.0 & & 1.0 & \\
\hline $1-500$ & 63.3 & 61.8 & 1.3 & $(0.9-1.8)$ & 59.9 & 16.6 & $(2.0-140.7)$ & 13.0 & $(1.6-108.0)$ \\
\hline$>500$ & 22.7 & 27.5 & 1.7 & $(1.1-2.6)$ & 39.4 & 30.2 & $(3.6-250.5)$ & 17.7 & $(2.1-152.8)$ \\
\hline Adjusted mean ${ }^{1}$ & 445.2 & 481.1 & $35.9^{2, *}$ & & 549.2 & $104.0^{2, *}$ & & $68.1^{2, *}$ & \\
\hline
\end{tabular}

Abbreviation: aOR, adjusted odds ratios; non-MetS, non-metabolic syndrome; pot-MetS, potential metabolic syndrome; MetS, metabolic syndrome (adolescents with $0,1-2$ and $\geq 3$ risk components for MetS were defined as non-MetS, pot-MetS and MetS, respectively); ${ }^{*} p<0.05 .{ }^{1}$ aORs and adjusted means were adjusted for age, gender, ethnicity, residential area, total calorie intake, alcohol drinking and cigarette smoking; ${ }^{2}$ Differences in adjusted means between the compared groups (pot-MetS and MetS vs. non-MetS, and MetS vs. pot-MetS); ${ }^{3}$ Bodyweight was classified according to adolescent age- and sex-specific BMI cut-off points for overweight and obesity determined by Taiwan's Ministry of Health and Welfare for adolescent growth charts.

The excess prevalence ratios of pot-MetS and MetS explained by the adolescent BMI for significant risk factors are shown in Table 4. The child BMI accounted for $66.9 \%-72.9 \%$ of the effect of parental overweight/obesity on pot-MetS, as well as for $23.5 \%-40.1 \%$ and $18.8 \%-50.5 \%$ of the association of parental T2DM and hypertension with pediatric pot-MetS and MetS, respectively. A high proportion of excess prevalence ratio of MetS $(60.3 \%)$ associated with $\geq 3 \mathrm{~h}$ /day of ST was explained by the child BMI. For heavy SSB consumption ( $>500 \mathrm{~mL} /$ day), the child BMI separately accounted for $23.6 \%$ and $16.9 \%$ of the effect on pot-MetS and MetS. Although the prevalence ratios between pot-MetS and MetS were heterogeneous for parental T2DM, hypertension, and adolescent low PA (aOR ratio, 2.6, 1.8, and 2.6 , respectively), more than $10 \%$ of the association was explained by the adolescent BMI $(44.4 \%$, $10.2 \%$, and $41.7 \%$, respectively).

Table 5 shows the synergistic effects of risk factors and adolescent body weight on pot-MetS and MetS. The prevalence ratio $(\mathrm{aOR}=8.6)$ of pot-MetS + MetS in SSB consumers who were overweight/obese was remarkably higher than the expected combined prevalence ratio $(\mathrm{aOR}=2.9)$ estimated using a multiplicative interaction model $(p=0.009)$. A significantly additive synergistic effect on pot-MetS + MetS was also observed among overweight/obesity adolescents with parental T2DM ( $\mathrm{SI}=4.2,95 \% \mathrm{CI}=1.4-12.4)$ and who had $\geq 1.5 \mathrm{~h} /$ day of $\mathrm{ST}(\mathrm{SI}=1.8,95 \% \mathrm{CI}=1.2-2.9)$. No significant interactions were found across the other risk factors for pot-MetS + MetS (Table S1). 
Table 4. Excess prevalence ratios of adolescent potential metabolic syndrome and metabolic syndrome explained by adolescent body mass index for significant parental and adolescent's risk factors.

\begin{tabular}{|c|c|c|c|c|c|c|c|c|c|c|c|c|}
\hline \multirow{3}{*}{ Factors } & \multicolumn{3}{|c|}{ Base Model $^{1,2}$} & \multicolumn{9}{|c|}{ Child zBMI-Adjusted Model ${ }^{3}$} \\
\hline & \multirow{2}{*}{$\begin{array}{c}\text { Pot-MetS } \\
\text { aOR }\end{array}$} & \multirow{2}{*}{$\begin{array}{c}\text { MetS } \\
\text { aOR }\end{array}$} & \multirow{2}{*}{$\begin{array}{c}\text { MetS vs. Pot-MetS } \\
\text { aOR }\end{array}$} & \multicolumn{2}{|c|}{ Pot-MetS } & \multirow{2}{*}{ EPRE $\%{ }^{4}$} & \multicolumn{2}{|c|}{ MetS } & \multirow{2}{*}{ EPRE $\%$} & \multicolumn{2}{|c|}{ MetS vs. Pot-MetS } & \multirow{2}{*}{ EPRE\% } \\
\hline & & & & aOR & $(95 \% \mathrm{CI})$ & & aOR & $(95 \% \mathrm{CI})$ & & $\mathrm{aOR}$ & $(95 \% \mathrm{CI})$ & \\
\hline \multicolumn{13}{|l|}{ Parental risk factors } \\
\hline Mother: OW + OB vs. NW & $1.5^{*}$ & $1.9^{*}$ & 1.3 & 1.2 & $(0.9-1.4)$ & 66.9 & 1.0 & $(0.4-2.7)$ & 95.6 & 0.8 & $(0.3-1.7)$ & na \\
\hline Diabetes mellitus: Yes vs. No & $1.6 *$ & $4.2 *$ & $2.6 *$ & 1.4 & $(0.8-2.3)$ & 40.1 & $2.6 *$ & $(1.0-6.5)$ & 50.5 & 1.9 & $(0.7-5.0)$ & 44.4 \\
\hline Hypertension: Yes vs. No & $1.5^{*}$ & $2.7^{*}$ & $1.8^{*}$ & 1.4 & $(0.99-1.9)$ & 23.5 & 2.4 * & $(1.2-4.6)$ & 18.8 & 1.7 & $(0.99-3.1)$ & 10.2 \\
\hline \multicolumn{13}{|l|}{ Adolescent lifestyle factors } \\
\hline \multicolumn{13}{|c|}{ Physical activity (MET·min/week) } \\
\hline$<952.4$ vs. $\geq 2140.5$ & 1.3 & $3.3 *$ & $2.6 *$ & 1.4 & $(0.9-2.0)$ & na & 2.6 & $(0.9-8.0)$ & 30.3 & 1.9 & $(0.6-5.9)$ & 41.7 \\
\hline \multicolumn{13}{|l|}{ Screen time (h/day) } \\
\hline $1.5-2.9$ vs. $<1.5$ & 1.2 & 1.5 & 1.2 & 1.3 & $(0.9-1.8)$ & na & 1.5 & $(0.5-4.7)$ & na & 1.2 & $(0.6-2.4)$ & na \\
\hline$\geq 3$ vs. $<1.5$ & 1.4 & $2.2 *$ & 1.5 & 1.4 & $(0.9-2.2)$ & na & 1.5 & $(0.6-3.6)$ & 60.3 & 1.0 & $(0.6-2.9)$ & na \\
\hline \multicolumn{13}{|l|}{ SSB intake (mL/day) } \\
\hline $1-500$ vs. Non-intake & 1.3 & $16.1 *$ & $12.6 *$ & 1.2 & $(0.9-1.8)$ & na & $18.9^{*}$ & $(1.7-207.5)$ & NA & $15.2 *$ & $(1.4-163.8)$ & NA \\
\hline$>500$ vs. Non-intake & $1.6^{*}$ & $26.9 *$ & $16.4^{*}$ & 1.5 & $(0.9-2.2)$ & 23.6 & 22.5 * & $(1.9-265.4)$ & 16.9 & $15.2 *$ & $(1.3-183.1)$ & 8.3 \\
\hline
\end{tabular}

Abbreviation: aOR, adjusted odds ratio; BMI, body mass index; EPRE, excess prevalence ratio explained; na, non-appreciated because the aOR obtained in the base model was not significant; NA, non-applicable because zBMI produced a negative effect, i.e., aOR was larger in the zBMI-adjusted models than that in the base models, zBMI did not explain any effect; NW, normal weight; OB, obesity; OW, overweight; SSB, sugar-sweetened beverage; non-MetS, non-metabolic syndrome; pot-MetS, potential metabolic syndrome; MetS, metabolic syndrome (adolescents with $0,1-2$ and $\geq 3$ risk components for MetS were defined as non-MetS, pot-MetS and MetS, respectively); ${ }^{*} p<0.05 .{ }^{1}$ In the base models for parental factors, aORs were adjusted for adolescent age, gender, ethnicity, residential area, total calorie intake, alcohol drinking and cigarette smoking, as well as physical activity, screen time and SSB intake; ${ }^{2}$ In the base models for adolescent lifestyle factors, aORs were adjusted for adolescent age, gender, ethnicity, residential area, total calorie intake, alcohol drinking and cigarette smoking, as well as parental overweight/obesity, diabetes mellitus and hypertension; ${ }^{3}$ aORs were obtained from the respective base model and additionally adjusted for child zBMI

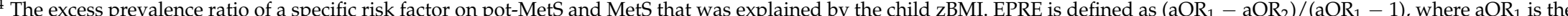
prevalence ratio obtained from the base model; $\mathrm{aOR}_{2}$ is the prevalence ratio after additionally adjusting for the child zBMI; and aOR $1-1$ is the excess prevalence ratio of a risk factor. 
Table 5. Combined and interaction effects of parental risk factors and adolescent lifestyle factors on adolescent potential metabolic syndrome and metabolic syndrome.

\begin{tabular}{|c|c|c|c|c|c|c|c|c|}
\hline \multirow{2}{*}{ Factor } & \multicolumn{2}{|c|}{ Non-MetS } & \multicolumn{2}{|c|}{ Pot-MetS + MetS } & \multicolumn{2}{|c|}{ Additive Model } & \multicolumn{2}{|c|}{ Multiplicative Model } \\
\hline & $\%$ & $\%$ & $\mathrm{aOR}^{1}$ & $(95 \% \mathrm{CI})$ & $\mathrm{SI}^{2}$ & $(95 \% \mathrm{CI})$ & EOR $^{2}$ & $p$-Value \\
\hline \multicolumn{9}{|c|}{ Parental risk factors and adolescent bodyweight } \\
\hline \multicolumn{9}{|c|}{ Father BW/BW } \\
\hline NW/NW & 43.2 & 23.9 & 1.0 & & & & & \\
\hline $\mathrm{NW} / \mathrm{OW}+\mathrm{OB}$ & 2.7 & 11.1 & 8.1 & $(4.4-14.9)$ & & & & \\
\hline $\mathrm{OW}+\mathrm{OB} / \mathrm{NW}$ & 46.6 & 34.9 & 1.3 & $(1.1-1.7)$ & & & & \\
\hline $\mathrm{OW}+\mathrm{OB} / \mathrm{OW}+\mathrm{OB}$ & 7.5 & 30 & 7.9 & $(4.4-14.0)$ & 0.9 & $(0.5-1.7)$ & 10.5 & 0.336 \\
\hline \multicolumn{9}{|l|}{ Mother BW/BW } \\
\hline NW/NW & 66.6 & 40.9 & 1.0 & & & & & \\
\hline $\mathrm{NW} / \mathrm{OW}+\mathrm{OB}$ & 6.6 & 21.5 & 6.4 & $(3.5-11.8)$ & & & & \\
\hline $\mathrm{OW}+\mathrm{OB} / \mathrm{NW}$ & 23.5 & 18.8 & 1.3 & $(0.9-1.7)$ & & & & \\
\hline $\mathrm{OW}+\mathrm{OB} / \mathrm{OW}+\mathrm{OB}$ & 3.4 & 18.8 & 9.6 & $(5.0-18.2)$ & 1.5 & $(0.8-2.8)$ & 8.3 & 0.641 \\
\hline \multicolumn{9}{|l|}{ Diabetes/BW } \\
\hline No/NW & 85.5 & 56.1 & 1.0 & & & & & \\
\hline $\mathrm{No} / \mathrm{OW}+\mathrm{OB}$ & 10.2 & 36.2 & 6.2 & $(3.6-10.7)$ & & & & \\
\hline Yes/NW & 4.0 & 2.8 & 1.2 & $(0.6-2.2)$ & & & & \\
\hline Yes/OW + OB & 0.3 & 5 & 23.8 & $(8.3-68.5)$ & 4.2 & $(1.4-12.4)$ & 7.4 & 0.08 \\
\hline \multicolumn{9}{|l|}{ Hypertension/BW } \\
\hline No/NW & 78.2 & 49.2 & 1.0 & & & & & \\
\hline $\mathrm{No} / \mathrm{OW}+\mathrm{OB}$ & 9.2 & 32.4 & 6.5 & $(3.8-10.8)$ & & & & \\
\hline Yes/NW & 11.3 & 9.7 & 1.4 & $(0.9-2.0)$ & & & & \\
\hline Yes/OW + OB & 1.4 & 8.7 & 11.2 & $(4.6-27.4)$ & 1.7 & $(0.9-3.5)$ & 9.1 & 0.477 \\
\hline \multicolumn{9}{|c|}{ Adolescent lifestyle factor and bodyweight } \\
\hline \multicolumn{9}{|c|}{ Physical activity (MET $\cdot \mathrm{min} /$ week)/BW } \\
\hline$\geq 952.4 / \mathrm{NW}$ & 28.0 & 16.5 & 1.0 & & & & & \\
\hline$\geq 952.4 / \mathrm{OW}+\mathrm{OB}$ & 4.5 & 13.2 & 5.6 & $(3.0-10.5)$ & & & & \\
\hline$<952.4 / \mathrm{NW}$ & 61.5 & 42.4 & 1.1 & $(0.8-1.4)$ & & & & \\
\hline$<952.4 / \mathrm{OW}+\mathrm{OB}$ & 6.0 & 28.0 & 8.0 & $(4.6-13.9)$ & 1.5 & $(0.8-2.7)$ & 6.2 & 0.298 \\
\hline \multicolumn{9}{|l|}{ Screen time $(\mathrm{h} /$ day $) / \mathrm{BW}$} \\
\hline$<1.5 / \mathrm{NW}$ & 44.0 & 29.1 & 1.0 & & & & & \\
\hline$<1.5 / \mathrm{OW}+\mathrm{OB}$ & 5.4 & 16.2 & 5.2 & $(2.7-10.0)$ & & & & \\
\hline$\geq 1.5 / \mathrm{NW}$ & 45.5 & 29.8 & 1.0 & $(0.7-1.5)$ & & & & \\
\hline$\geq 1.5 / \mathrm{OW}+\mathrm{OB}$ & 5.1 & 25.0 & 8.8 & $(4.8-16.4)$ & 1.8 & $(1.2-2.9)$ & 5.2 & 0.067 \\
\hline \multicolumn{9}{|l|}{ SSB intake/BW } \\
\hline No/NW & 12.3 & 7.5 & 1.0 & & & & & \\
\hline $\mathrm{No} / \mathrm{OW}+\mathrm{OB}$ & 1.8 & 2.4 & 2.6 & $(1.0-6.5)$ & & & & \\
\hline Yes/NW & 77.2 & 51.4 & 1.1 & $(0.8-1.7)$ & & & & \\
\hline Yes/OW + OB & 8.8 & 38.7 & 8.6 & $(4.3-17.3)$ & 4.4 & $(1.6-12.6)$ & 2.9 & 0.009 \\
\hline
\end{tabular}

Abbreviation: BW, bodyweight; NW, normal weight; OB, obesity; OW, overweight; SSB, sugar-sweetened beverage. non-MetS, non-metabolic syndrome; pot-MetS, potential metabolic syndrome; MetS, metabolic syndrome. Adolescents with $0,1-2$ and $\geq 3$ risk components for MetS were defined as non-MetS, pot-MetS and MetS, respectively. ${ }^{1}$ aORs were adjusted for age, gender, ethnicity, residential area, total calorie intake, alcohol drinking and cigarette smoking; ${ }^{2}$ Synergism index (SI) was estimated by additive interaction models. Expected odds ratio (EOR) was estimated by multiplicative interaction models.

\section{Discussion}

The present findings reveal the association between parental overweight, T2DM, and hypertension and pediatric adiposity and lifestyle factors with the clustering of cardiometabolic risk factors among adolescents. This study also revealed the mediating and modifying effects of pediatric overweight on the association of familial and individual factors with adolescent pot-MetS and MetS.

Family linkage studies have reported that cardiovascular risk factors, such as obesity and hyperlipidemia, incline to cluster within families [9-11]. In a longitudinal parent-child dyad study, a 14.2-fold higher risk of eligibility for bariatric surgery was observed among obese children with an obese parent compared with children with non-obese families [12]. This study further revealed that parental overweight/obesity may predispose children to a higher risk of pot-MetS $(\mathrm{aOR}=1.5 \mathrm{in}$ both father and mother) and MetS (aOR $=2.2$ in the mother). Recently, cardiometabolic abnormalities among children have been associated with parental MetS-associated diseases [37,38]. In India, a higher risk of being overweight, low HDL-C, high BP, and glucose intolerance was observed in adolescents with parental T2DM [38]. In Iran, a 4.5-fold risk of MetS was observed in adolescents with both parents 
having MetS. Our study revealed that a parental history of T2DM and hypertension was associated with pediatric pot-MetS and MetS, and the risk of MetS was higher than that of pot-MetS (aOR ratio, 3.0 and 1.8, respectively) in adolescents whose parents had the two MetS-related diseases.

This study revealed that the adolescent BMI accounted for a majority of the effects of parental overweight/obesity on pediatric pot-MetS and MetS (66.9\%-72.9\% for pot-MetS in both parents and $95.6 \%$ for MetS in the mother). This emphasizes the potential effect of a shared obesogenic environment across generations. Although adolescent BMI also accounted for $18.8 \%-50.5 \%$ of the increased risks of parental T2DM and hypertension on pediatric MetS, the generational effect of the two MetS-associated diseases remained significant (zBMI-adjusted OR $=2.6$ and 2.4, respectively; $p<0.03$ ), implying the existence of non-obesity-mediated mechanisms. These results were consistent with those of a recent study, in which many cardiometabolic risk factors significantly correlated between parents and children even after adjustments for their BMIs [10]. Unhealthy lifestyle factors are the major determinants of obesity, diabetes, and cardiovascular diseases [20,39]. Considering these findings that reveal the clustering of cardiometabolic risk factors and diseases within families, establishing a family-based healthy lifestyle is crucial for preventing and resolving the clustering of MetS components within families. Our study identified a notable modifying effect of parental T2DM on the risk of pot-MetS + MetS for adolescent overweight/obesity by using an additive interaction model (combined $\mathrm{aOR}=23.8$ ). This indicates that overweight adolescents with parental T2DM are a high-risk group for the clustering of cardiometabolic abnormalities and are the primary target to be intervened with a healthy lifestyle.

Consistent with our findings, a previous study revealed the detrimental effect of a low level of PA on cardiometabolic disorders [13]. A recent study suggested that, independent of PA levels, screen-based sedentary behavior is an emerging risk factor for adiposity and cardiometabolic diseases among children and youth [40]. In a 12-year follow-up study, a higher ST in childhood was observed to be associated with a higher level of BMI, triglycerides, and MetS Z-score in early adulthood [14]. In a longitudinal study with multiple life course investigations, an increased number of life periods of frequent TV viewing during adolescence and early adulthood increased the cardiometabolic risk in mid-adulthood [41]. Similarly, our study revealed that adolescents with $\geq 3 \mathrm{~h} /$ day of ST had a 2.2 -fold higher risk of MetS; however, an increase of $60.3 \%$ in the risk was explained by the child BMI. In a prospective study with mediation analysis, low PA was identified to partially mediate the adverse effect of ST on adiposity, and adiposity was observed to strongly mediate the association between ST and the total-to-HDL-C ratio (a cardiometabolic marker) [42]. ST is a modifiable lifestyle factor, which may promote PA- and adiposity-mediated effects on the cardiometabolic risk. Directing public health efforts toward reducing this sedentary behavior is a crucial concern in adolescent cardiometabolic health care.

Our study revealed that adolescents who consumed $>500 \mathrm{~mL} /$ day of SSB had elevated parental risk factors and child BMI- and total calorie intake-adjusted MetS risk (aOR = 15.2 and 22.5, respectively, compared with adolescents with pot-MetS and non-MetS adolescents, Table 4). The association between a high consumption of SSB and the development of hypertension, dyslipidemia, dysglycemia, insulin resistance, and hyperuricemia have been reported in recent epidemiological studies in adolescents $[4,24,43-46]$. Despite specific controversies, some mechanisms have been proposed to support the argument that excess sugar consumption increases cardiometabolic risk. The direct pathway is associated with disordered hepatic uptake and unregulated fructose metabolism, and the indirect pathway is associated with weight gain and fat accumulation [47]. Moreover, this study revealed that the risk of pot-MetS + MetS associated with SSB consumption was multiplicatively enhanced among adolescents with overweight/obesity ( $p$ for multiplicative interaction $<0.05$ ), supporting the hypothesis that weight gain is associated with the development and aggregation of cardiometabolic risk factors in a mechanistic manner and thus increasing the effect of added sugar in beverages. 
Passive smoking has been associated with an increased risk of MetS and a few cardiometabolic risk factors among adolescents [48,49]. In the 2007-2010 National Health and Nutrition Examination Survey, the joint risk of adolescent MetS from high exposure to passive smoking and low levels of vitamin E or omega-3 polyunsaturated fatty acids was higher than that expected from the individual risks [50]. However, in this study, no significant effects of parental smoking on adolescent MetS were identified.

This study has several strengths. First, according to our review of relevant literature, this study is the first to evaluate the associations of parental and pediatric risk factors with the clustering of cardiometabolic risk factors among Taiwanese adolescents; moreover, a large representative data set was used. Second, because highly trained staff members cautiously explained the data filling protocol and because participants were unaware of the research hypothesis, reporting bias should be limited; even if it exists, the association measure should be biased toward the null. However, this study has several limitations. First, although anthropometric measurements and lifestyle factors were obtained three weeks before collecting clinical blood samples, the cross-sectional study design prevents any cause-effect determination. Second, parental blood samples were not collected, thus limiting the valuation of familial aggregation for all MetS components. Finally, participants with pot-MetS and MetS were combined because of the low prevalence of MetS, thus limiting interaction assessments between risk factors for adolescents with MetS.

\section{Conclusions}

Parental overweight and cardiometabolic diseases and pediatric sedentary and high sugar-intake lifestyles correlate with the development of adolescent MetS, and an elevated child BMI explains a part of these associations. Pediatric adiposity might be multiplicatively associated with SSB consumption for enhancing the MetS prevalence ratio among adolescents.

Supplementary Materials: The following are available online at http://www.mdpi.com/2072-6643/8/9/567/s1, Table S1: Combined and interaction effects of adolescents' lifestyle factors on potential metabolic syndrome and metabolic syndrome. Figure S1: Distribution of overweight and obesity among adolescents with non-metabolic syndrome (non-MetS), potential metabolic syndrome (pot-MetS) and metabolic syndrome (MetS).

Acknowledgments: This work was supported by the Taiwan National Science Council (NSC 96-2314-B-037-041-MY3, NSC99-2314-B-037-046-MY3, and NSC 102-2314-B-037-060), the Taiwan Ministry of Science and Technology (MOST 103-2314-B-037-019-MY3), and partially supported by the grants from the Kaohsiung Medical University Hospital research foundation (KMHK-102-035, KMUH103-3M59, and KMHK-104-4M50) and the Research Center for Environmental Medicine, Kaohsiung Medical University (KMU-TP104A13).

Author Contributions: L.C.H. conceived and designed the experiments; T.S., H.Y.C., W.P.W., Y.Y.C., C.T.F., H.H.L., W.Y.L., C.Y.W. and H.C.T. performed the experiments; L.C.Y., L.W.T. and L.C.H. analyzed the data; L.C.Y. and L.C.H. wrote the paper.

Conflicts of Interest: The authors declare no conflict of interest.

\section{Abbreviations}

The following abbreviations are used in this manuscript:

$\begin{array}{ll}\text { aOR } & \text { adjusted odds ratio } \\ \text { BMI } & \text { body mass index } \\ \text { BP } & \text { blood pressure } \\ \text { CI } & \text { confidence interval } \\ \text { HDL-C } & \text { metdensity lipoprotein cholesterol } \\ \text { MET } & \text { metabolic equivalent task } \\ \text { MetS } & \text { non-metabolic syndrome } \\ \text { non-MetS } & \text { physical activity } \\ \text { PA } & \text { potential metabolic syndrome } \\ \text { pot-MetS } & \text { synergism index } \\ \text { SI } & \text { sugar-sweetened beverage } \\ \text { SSB } & \text { screen time } \\ \text { ST } & \text { type 2 diabetes mellitus }\end{array}$




\section{References}

1. Naghavi, M.; Wang, H.; Lozano, R.; Davis, A.; Liang, X.; Zhou, M.; Vollset, S.E.; Ozgoren, A.A.; Abdalla, S.; Abd-Allah, F.; et al. Global, regional, and national age-sex specific all-cause and cause-specific mortality for 240 causes of death, 1990-2013: A systematic analysis for the global burden of disease study 2013. Lancet 2015, 385, 117-171.

2. The Global Burden of Metabolic Risk Factors for Chronic Diseases Collaboration. Cardiovascular disease, chronic kidney disease, and diabetes mortality burden of cardiometabolic risk factors from 1980 to 2010 : A comparative risk assessment. Lancet Diabetes Endocrinol. 2014, 2, 634-647.

3. May, A.L.; Kuklina, E.V.; Yoon, P.W. Prevalence of cardiovascular disease risk factors among US adolescents, 1999-2008. Pediatrics 2012, 129, 1035-1041. [CrossRef] [PubMed]

4. $\quad$ Lin, W.T.; Huang, H.L.; Huang, M.C.; Chan, T.F.; Ciou, S.Y.; Lee, C.Y.; Chiu, Y.W.; Duh, T.H.; Lin, P.L.; Wang, T.N.; et al. Effects on uric acid, body mass index and blood pressure in adolescents of consuming beverages sweetened with high-fructose corn syrup. Int. J. Obes. 2013, 37, 532-539. [CrossRef] [PubMed]

5. Chan, T.F.; Lin, W.T.; Huang, H.L.; Lee, C.Y.; Wu, P.W.; Chiu, Y.W.; Huang, C.C.; Tsai, S.; Lin, C.L.; Lee, C.H. Consumption of sugar-sweetened beverages is associated with components of the metabolic syndrome in adolescents. Nutrients 2014, 6, 2088-2103. [CrossRef] [PubMed]

6. Bao, W.; Srinivasan, S.R.; Valdez, R.; Greenlund, K.J.; Wattigney, W.A.; Berenson, G.S. Longitudinal changes in cardiovascular risk from childhood to young adulthood in offspring of parents with coronary artery disease: The Bogalusa heart study. JAMA 1997, 278, 1749-1754. [CrossRef] [PubMed]

7. Magnussen, C.G.; Koskinen, J.; Chen, W.; Thomson, R.; Schmidt, M.D.; Srinivasan, S.R.; Kivimaki, M.; Mattsson, N.; Kahonen, M.; Laitinen, T.; et al. Pediatric metabolic syndrome predicts adulthood metabolic syndrome, subclinical atherosclerosis, and type 2 diabetes mellitus but is no better than body mass index alone: The Bogalusa heart study and the cardiovascular risk in young finns study. Circulation 2010, 122, 1604-1611. [CrossRef] [PubMed]

8. Magnussen, C.G.; Koskinen, J.; Juonala, M.; Chen, W.; Srinivasan, S.R.; Sabin, M.A.; Thomson, R.; Schmidt, M.D.; Nguyen, Q.M.; Xu, J.H.; et al. A diagnosis of the metabolic syndrome in youth that resolves by adult life is associated with a normalization of high carotid intima-media thickness and type 2 diabetes mellitus risk: The Bogalusa heart and cardiovascular risk in young finns studies. J. Am. Coll. Cardiol. 2012, 60, 1631-1639. [CrossRef] [PubMed]

9. Cooper, R.; Pinto Pereira, S.M.; Power, C.; Hypponen, E. Parental obesity and risk factors for cardiovascular disease among their offspring in mid-life: Findings from the 1958 british birth cohort study. Int. J. Obes. 2013, 37, 1590-1596. [CrossRef] [PubMed]

10. Halvorsen, T.; Moran, A.; Jacobs, D.R., Jr.; Steffen, L.M.; Sinaiko, A.R.; Zhou, X.; Steinberger, J. Relation of cardiometabolic risk factors between parents and children. J. Pediatr. 2015, 167, 1049-1056. [CrossRef] [PubMed]

11. Vik, K.L.; Romundstad, P.; Nilsen, T.I. Tracking of cardiovascular risk factors across generations: Family linkage within the population-based hunt study, Norway. J. Epidemiol. Community Health 2013, 67, 564-570. [CrossRef] [PubMed]

12. Juonala, M.; Sabin, M.A.; Burgner, D.; Cheung, M.; Kahonen, M.; Hutri-Kahonen, N.; Lehtimaki, T.; Jokinen, E.; Koskinen, J.; Tossavainen, P.; et al. Increased body mass index in parent-child dyads predicts the offspring risk of meeting bariatric surgery criteria. J. Clin. Endocrinol. Metab. 2015, 100, 4257-4263. [CrossRef] [PubMed]

13. Ekelund, U.; Luan, J.; Sherar, L.B.; Esliger, D.W.; Griew, P.; Cooper, A.; International Children's Accelerometry Database (ICAD) Collaborators. Moderate to vigorous physical activity and sedentary time and cardiometabolic risk factors in children and adolescents. JAMA 2012, 307, 704-712. [CrossRef] [PubMed]

14. Grontved, A.; Ried-Larsen, M.; Moller, N.C.; Kristensen, P.L.; Wedderkopp, N.; Froberg, K.; Hu, F.B.; Ekelund, U.; Andersen, L.B. Youth screen-time behaviour is associated with cardiovascular risk in young adulthood: The European youth heart study. Eur. J. Prev. Cardiol. 2014, 21, 49-56. [CrossRef] [PubMed]

15. Pan, Y.; Pratt, C.A. Metabolic syndrome and its association with diet and physical activity in US adolescents. J. Am. Diet. Assoc. 2008, 108, 276-286. [CrossRef] [PubMed] 
16. Robinson, S.; Daly, R.M.; Ridgers, N.D.; Salmon, J. Screen-based behaviors of children and cardiovascular risk factors. J. Pediatr. 2015, 167, 1239-1245. [CrossRef] [PubMed]

17. Sanchez, A.A.; Levy, P.T.; Sekarski, T.J.; Arbelaez, A.M.; Hildebolt, C.F.; Holland, M.R.; Singh, G.K. Markers of cardiovascular risk, insulin resistance, and ventricular dysfunction and remodeling in obese adolescents. J. Pediatr. 2015, 166, 660-665. [CrossRef] [PubMed]

18. Weiss, R.; Dziura, J.; Burgert, T.S.; Tamborlane, W.V.; Taksali, S.E.; Yeckel, C.W.; Allen, K.; Lopes, M.; Savoye, M.; Morrison, J.; et al. Obesity and the metabolic syndrome in children and adolescents. N. Engl. J. Med. 2004, 350, 2362-2374. [CrossRef] [PubMed]

19. Leech, R.M.; McNaughton, S.A.; Timperio, A. The clustering of diet, physical activity and sedentary behavior in children and adolescents: A review. Int. J. Behav. Nutr. Phys. Act. 2014, 11, 4. [CrossRef] [PubMed]

20. Mozaffarian, D. Dietary and policy priorities for cardiovascular disease, diabetes, and obesity: A comprehensive review. Circulation 2016, 133, 187-225. [CrossRef] [PubMed]

21. Vale, S.; Trost, S.G.; Rego, C.; Abreu, S.; Mota, J. Physical activity, obesity status, and blood pressure in preschool children. J. Pediatr. 2015, 167, 98-102. [CrossRef] [PubMed]

22. Liou, T.H.; Huang, Y.C.; Chou, P. Prevalence and secular trends in overweight and obese taiwanese children and adolescents in 1991-2003. Ann. Hum. Biol. 2009, 36, 176-185. [CrossRef] [PubMed]

23. Chan, T.F.; Lin, W.T.; Chen, Y.L.; Huang, H.L.; Yang, W.Z.; Lee, C.Y.; Chen, M.H.; Wang, T.N.; Huang, M.C.; Chiu, Y.W.; et al. Elevated serum triglyceride and retinol-binding protein 4 levels associated with fructose-sweetened beverages in adolescents. PLoS ONE 2014, 9, e82004. [CrossRef] [PubMed]

24. Lin, W.T.; Chan, T.F.; Huang, H.L.; Lee, C.Y.; Tsai, S.; Wu, P.W.; Yang, Y.C.; Wang, T.N.; Lee, C.H. Fructose-rich beverage intake and central adiposity, uric acid and pediatric insulin resistance. J. Pediatr. 2016, 171, 90-96. [CrossRef] [PubMed]

25. Chu, N.F. Prevalence of obesity in Taiwan. Obes. Rev. 2005, 6, 271-274. [CrossRef] [PubMed]

26. Ridley, K.; Ainsworth, B.E.; Olds, T.S. Development of a compendium of energy expenditures for youth. Int. J. Behav. Nutr. Phys. Act. 2008, 5, 45. [CrossRef] [PubMed]

27. Taiwanese Food and Nutrients Databank. Available online: https://consumer.Fda.Gov.Tw/foodanalysis / ingredients.Htm (accessed on 10 October 2012). (In Chinese)

28. Recommended Values for Children and Adolescent Growing Body Mass Index. Available online: http:/ / www.Hpa.Gov.Tw/bhpnet/web/healthtopic/topicarticle.Aspx?Id=201308300012\&parentid= 201109290001 (accessed on 31 August 2016). (In Chinese)

29. Perloff, D.; Grim, C.; Flack, J.; Frohlich, E.D.; Hill, M.; McDonald, M.; Morgenstern, B.Z. Human blood pressure determination by sphygmomanometry. Circulation 1993, 88, 2460-2470. [CrossRef] [PubMed]

30. Allain, C.C.; Poon, L.S.; Chan, C.S.; Richmond, W.; Fu, P.C. Enzymatic determination of total serum cholesterol. Clin. Chem. 1974, 20, 470-475. [PubMed]

31. Alberti, K.G.; Eckel, R.H.; Grundy, S.M.; Zimmet, P.Z.; Cleeman, J.I.; Donato, K.A.; Fruchart, J.C.; James, W.P.; Loria, C.M.; Smith, S.C., Jr.; et al. Harmonizing the metabolic syndrome: A joint interim statement of the international diabetes federation task force on epidemiology and prevention; national heart, lung, and blood institute; american heart association; world heart federation; international atherosclerosis society; and international association for the study of obesity. Circulation 2009, 120, 1640-1645. [PubMed]

32. Lee, C.H.; Wu, D.C.; Lee, J.M.; Wu, I.C.; Goan, Y.G.; Kao, E.L.; Huang, H.L.; Chan, T.F.; Chou, S.H.; Chou, Y.P.; et al. Anatomical subsite discrepancy in relation to the impact of the consumption of alcohol, tobacco and betel quid on esophageal cancer. Int. J. Cancer 2007, 120, 1755-1762. [CrossRef] [PubMed]

33. Mickey, R.M.; Greenland, S. The impact of confounder selection criteria on effect estimation. Am. J. Epidemiol. 1989, 129, 125-137. [PubMed]

34. Brancati, F.L.; Kao, W.H.; Folsom, A.R.; Watson, R.L.; Szklo, M. Incident type 2 diabetes mellitus in African American and white adults: The atherosclerosis risk in communities study. JAMA 2000, 283, 2253-2259. [CrossRef] [PubMed]

35. Hosmer, D.W.; Lemeshow, S. Confidence interval estimation of interaction. Epidemiology 1992, 3, 452-456. [CrossRef] [PubMed]

36. Lee, C.H.; Lee, J.M.; Wu, D.C.; Hsu, H.K.; Kao, E.L.; Huang, H.L.; Wang, T.N.; Huang, M.C.; Wu, M.T. Independent and combined effects of alcohol intake, tobacco smoking and betel quid chewing on the risk of esophageal cancer in Taiwan. Int. J. Cancer 2005, 113, 475-482. [CrossRef] [PubMed] 
37. Azizi, F.; Farahani, Z.K.; Ghanbarian, A.; Sheikholeslami, F.; Mirmiran, P.; Momenan, A.A.; Asl, S.Z.; Hadaegh, F.; Eskandari, F. Familial aggregation of the metabolic syndrome: Tehran lipid and glucose study. Ann. Nutr. Metab. 2009, 54, 189-196. [CrossRef] [PubMed]

38. Anjana, R.M.; Lakshminarayanan, S.; Deepa, M.; Farooq, S.; Pradeepa, R.; Mohan, V. Parental history of type 2 diabetes mellitus, metabolic syndrome, and cardiometabolic risk factors in Asian Indian adolescents. Metabolism 2009, 58, 344-350. [CrossRef] [PubMed]

39. Gadiraju, T.V.; Patel, Y.; Gaziano, J.M.; Djousse, L. Fried food consumption and cardiovascular health: A review of current evidence. Nutrients 2015, 7, 8424-8430. [CrossRef] [PubMed]

40. Tremblay, M.S.; LeBlanc, A.G.; Kho, M.E.; Saunders, T.J.; Larouche, R.; Colley, R.C.; Goldfield, G.; Connor Gorber, S. Systematic review of sedentary behaviour and health indicators in school-aged children and youth. Int. J. Behav. Nutr. Phys. Act. 2011, 8, 98. [CrossRef] [PubMed]

41. Wennberg, P.; Gustafsson, P.E.; Howard, B.; Wennberg, M.; Hammarstrom, A. Television viewing over the life course and the metabolic syndrome in mid-adulthood: A longitudinal population-based study. J. Epidemiol. Community Health 2014, 68, 928-933. [CrossRef] [PubMed]

42. Berentzen, N.E.; Smit, H.A.; van Rossem, L.; Gehring, U.; Kerkhof, M.; Postma, D.S.; Boshuizen, H.C.; Wijga, A.H. Screen time, adiposity and cardiometabolic markers: Mediation by physical activity, not snacking, among 11-year-old children. Int. J. Obes. 2014, 38, 1317-1323. [CrossRef] [PubMed]

43. Nguyen, S.; Choi, H.K.; Lustig, R.H.; Hsu, C.Y. Sugar-sweetened beverages, serum uric acid, and blood pressure in adolescents. J. Pediatr. 2009, 154, 807-813. [CrossRef] [PubMed]

44. Wang, J.; Light, K.; Henderson, M.; O'Loughlin, J.; Mathieu, M.E.; Paradis, G.; Gray-Donald, K. Consumption of added sugars from liquid but not solid sources predicts impaired glucose homeostasis and insulin resistance among youth at risk of obesity. J. Nutr. 2014, 144, 81-86. [CrossRef] [PubMed]

45. Gulati, S.; Misra, A. Sugar intake, obesity, and diabetes in India. Nutrients 2014, 6, 5955-5974. [CrossRef] [PubMed]

46. Nasreddine, L.; Naja, F.; Akl, C.; Chamieh, M.C.; Karam, S.; Sibai, A.M.; Hwalla, N. Dietary, lifestyle and socio-economic correlates of overweight, obesity and central adiposity in lebanese children and adolescents. Nutrients 2014, 6, 1038-1062. [CrossRef] [PubMed]

47. Stanhope, K.L. Sugar consumption, metabolic disease and obesity: The state of the controversy. Crit. Rev. Clin. Lab. Sci. 2016, 53, 52-67. [CrossRef] [PubMed]

48. Xie, B.; Palmer, P.H.; Pang, Z.; Sun, P.; Duan, H.; Johnson, C.A. Environmental tobacco use and indicators of metabolic syndrome in Chinese adults. Nicotine Tob. Res. 2010, 12, 198-206. [CrossRef] [PubMed]

49. Kelishadi, R.; Noori, A.; Qorbani, M.; Rahimzadeh, S.; Djalalinia, S.; Shafiee, G.; Motlagh, M.E.; Ardalan, G.; Ansari, H.; Asayesh, H.; et al. Are active and passive smoking associated with cardiometabolic risk factors in adolescents? The CASPIAN-III Study. Paediatr. Int. Child Health 2016, 1-8. [CrossRef] [PubMed]

50. Moore, B.F.; Clark, M.L.; Bachand, A.; Reynolds, S.J.; Nelson, T.L.; Peel, J.L. Interactions between diet and exposure to secondhand smoke on metabolic syndrome among children: Nhanes 2007-2010. J. Clin. Endocrinol. Metab. 2016, 101, 52-58. [CrossRef] [PubMed]

(c) 2016 by the authors; licensee MDPI, Basel, Switzerland. This article is an open access article distributed under the terms and conditions of the Creative Commons Attribution (CC-BY) license (http://creativecommons.org/licenses/by/4.0/). 